\title{
Settlement and Capacity Analysis of Land Support Development on Flyover in Large City; Pekanbaru, Indonesia
}

\author{
Husnul Kausarian ${ }^{1}{ }^{*}$, Evan Trionaldi ${ }^{1}$, Taufan Khalif Arrahman ${ }^{1}$, Dewandra Bagus Eka Putra ${ }^{1}$, \\ Batara $^{1}$ \\ ${ }^{I}$ Department of Geological Engineering, Universitas Islam Riau, Pekanbaru, Riau 28284, Indonesia.
}

* Corresponding author : husnulkausarian@eng.uir.ac.id

Tel.:+62-761-674674; fax: +62-761-674834

Received: May 16, 2020; Accepted: Jun 19, 2020

DOI 10.25299/jgeet.2020.5.2.5048

\begin{abstract}
The study area located on the street of Soebrantas to Soekarno Hatta Street, with the coordinate position of $0^{\circ} 30^{\prime} 0.799^{\prime N} 101^{\circ} 24^{\prime} 57.88$ "E - $0^{\circ} 30^{\prime} 0.16$ "N $101^{\circ} 24^{\prime} 53.17$ "E in Pekanbaru City, Indonesia. The development that will Conduct flyovers in this area became the basis of this research. The main study of this research is to find out how an Atterberg's boundaries, compressibility, and the likelihood of a ground decline in drill 1 use the value of N SPT to match with the purpose of this study. Which is (1) to know the large grain size of soil samples, (2) Knowing the value of the liquid limit, the plastic boundary, and the plastic index of the soil samples, (3) Knowing the possibility of land degradation in the research area, (4) Power capacity analysis of ground support (5) Knowing the decline of modeling using the Plaxis 2D method (6) knows the relationship of decreasing values based on NSPT and Plaxis (7) Knowing the relationship of sieve analysis and Attaberg limit with decreased results. Methods of data retrieval have done with soil testing in the field and soil testing in the laboratories. A comprehensive analysis of the grain has done with sieve analysis. Plastic boundary, liquid, and plastic boundary indices with method Attaberg limit. Decreased analysis and Power capacity analysis of ground support with NSPT value tests.
\end{abstract}

Keywords: Sieve Analysis, Atterberg Limit, the capacity of soil support and settlement, N-SPT, Plaxis 2D Modelling, Flyover

\section{Introduction}

To support the economic growth activities of the Government of Indonesia, planning various infrastructure development programs ranging from the construction of toll roads, bridges, airports, docks, ports, canals, and so on (Salim and Negara, 2018; Laksono et al., 2018; Persada et al., 2018; Hamid et al., 2018). The development of infrastructure increased the confortivity, and reduce the gap between each region. The need for development land continues to grow so that the construction is forcing to established on the area that is fewer conditions such as soft soil.

Construction of the flyover will be implemented in this area to be the basis of this research. To find out how the Atterberg boundaries, compressibility, and likelihood of falling ground using the value of N SPT count (Wafi et al., 2018; Kuzu et al., 2020; Bautista et al., 2019; Kumar et al., 2017).

\section{Study Area and Background}

Based On Regional Geological map of sheet Pekanbaru (Clarke et al., 1982). The research area lies in the Minas Formation, precisely located at coordinates $0^{\circ} 30^{\prime} 0.79$ "N 101 ○ 24 ' 57.88 " E-0 30 ' 0.16 "N $101^{\circ} 24$ ' 53.17 " E

The Minas Formation is a quarter precipitate, precipitating in unaligned above the Petani formation,

the formation consists of a coating that is in the dominance of the Batupasir and occasionally appears a thin layer of clay. The formation was from Miocene to the Plistosen and precipitated in the fluvial-alluvium environment.

\section{Methodology}

\subsection{Research Object}

To conduct all the research methodology, we summarize all the step of research follows:

1. The grain size of the ground (Sieve Analysis) is a test of filtering soil samples through a set of the sieve.

2. Liquid limit (liquid Limit) is the moisture content on the boundary between the liquid state and the plastic state.

3. Plastic limit is the moisture content at the lower limit with plastic.

4. The Atterberg limit relationship with carrying capacity.

5. Modelling power support using Plaxis 2D

\subsection{Sieve Analysis}

Sieve Analysis (Bardet, 1997; Gupta et al., 2016; Ubani et al., 2018; Ruiz-Martínez et al., 2016) aims to determine the type of soil that is graded poorly, graded uniform and graded well. At once to know the grain size on the ground. The formula of Sieve Analysis is as follows:

$$
R_{n}=\frac{W_{n}}{W_{t}} \times 100 \%
$$

Where:

$\mathrm{Rn}=$ amount of unloaded weight $\mathrm{Wn}=$ Weight

$\mathrm{Wt}=$ Cup Weight

\subsection{Atterberg Limit}

The Atterberg Limit Test is a method used to describe the nature of the fine-grained soil context on varying waterlevels. The soil has certain conditions, namely from liquid to frozen state (Deng et al., 2017; Rehman et al., 2019). 


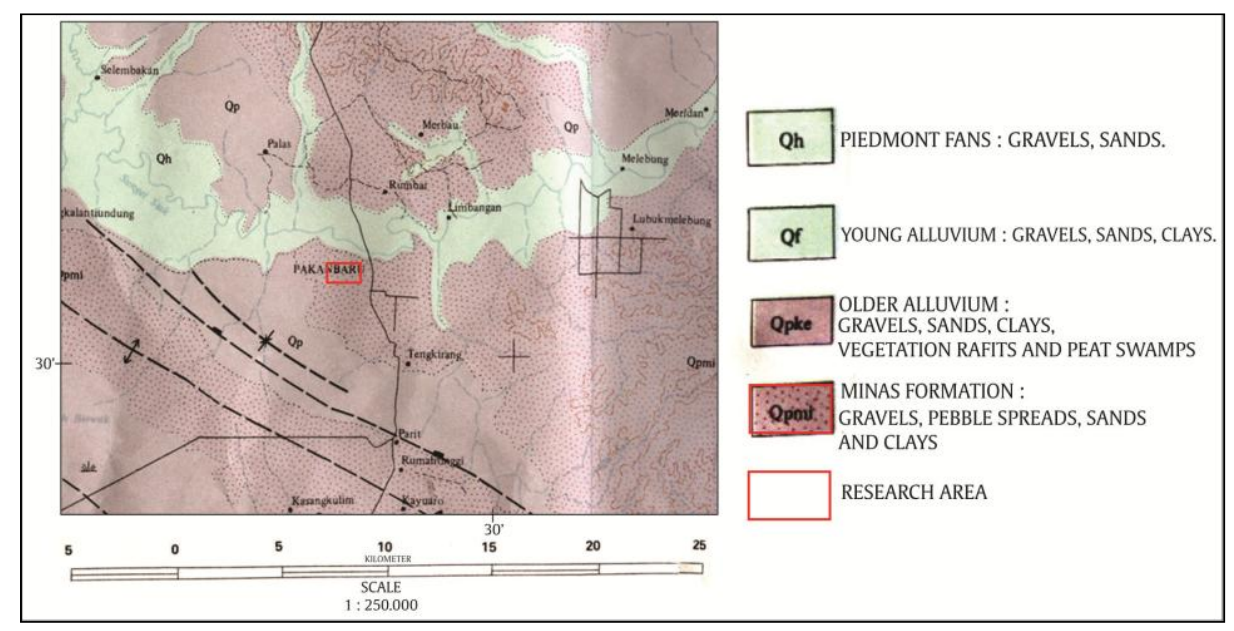

Fig. 1. Regional Geological Map of research Area.

\subsubsection{Liquid Limit}

The liquid limit is the groundwater level (Chai et al., 2017) at the liquid limit, and the plastic boundary or the maximum moisture content where the soil has a minimum slide is at the 25th beat with the Cassagrande tool. Liquid boundaries defined as the lowest moisture content in which the soil is in a liquid state or a condition where the soil changes from liquid to plastic:

$$
\mathrm{LL}=\frac{W-P L}{L L-P L}
$$

Where:

LL $=$ Liquid Limit

$\mathrm{W}=$ weight of soil samples

$\mathrm{PL}=$ Plastic Limit

\subsubsection{Plastic Limit}

Plastic limits defined as the moisture content in the position between the plastic and semi-solid (Hamzaban et al., 2019), which is\% water content where the ground with a cylinder diameter of $3.2 \mathrm{~mm}$ begins to crack - cracks when rolled. The plastic boundary can be determined by simple testing by rolling several soils using the soil repeatedly into an ellipsoidal form. Soil sample water content where the ground starts cracking fractures are defined as plastic boundaries:

$$
\mathrm{IP}=\mathrm{LL}-\mathrm{PL}
$$

Where:

$$
\text { IP = Plastic Index }
$$

$\mathrm{LL}=$ Liquid Limit

$\mathrm{PL}=$ Plastic Limit

\subsubsection{Plasticity Index}

The plasticity index demonstrates the nature of soil saturation. If the value of the PI is high, then the soil contains a lot of clay, then if the PI value is low, the soil contains muchsilt. The characteristic and nature of silt are with the moisture content that decreases minimal soil will dry. The plasticity index PI is the difference between the liquid limit and the plastic boundary of the soil.

\subsection{Capacity Analysis for Support And Decrease Soil}

If the soil is experiencing a load like a foundation burden, the soil will experience distortion or decline. If this burden is augmented, the reduction also increases. Finally, at one time, there was a condition that, at a fixed load, the foundation suffered a considerable decline. This condition indicates that the support capacity has occurred.

\subsection{Analysisof N-SPT (Standard Penetration Test)}

Methods carried out in conjunction with drilling to know both ground dynamic resistance and sampling, which is interrupted by the SPT test. The technique consists of a thick cold-tube beating test into the ground, accompanied by a measurement of the number of strokes for inserting a deep-side tube $300 \mathrm{~mm}$ vertically.

\subsection{Soil Reduction Analysis}

The decreasing calculation stated based on Bowles Theory (1977). The Bowles theory is the result of the modifying of the Meyerhoff theory. Bowles considers the Meyerhoff theory to be overly cautious, resulting in considerable decline. So Bowles recommend for better improvement is as follows:

$$
\begin{aligned}
& S_{i}=\frac{2,5 q}{N} \\
& S_{i}=\frac{4 q}{N}\left(\frac{B}{B+1}\right)^{2}
\end{aligned}
$$

Where:

$\mathrm{Si}=$ Lower Foundation (inch)

$\mathrm{Q}=$ load intensity $(\mathrm{kip} / \mathrm{ft} 2)$

$\mathrm{N}=$ number of SPT test punch

$\mathrm{B}=$ width of foundation $(\mathrm{ft})$

\subsection{Analysis Of Power Capacity Supports Depth Of Land (Meyerhof 1956 - 1974)}

With QA is the capacity to support net permit in $\mathrm{kN} / \mathrm{m}^{2}$, for a decrease of $2.54 \mathrm{~cm}$. The Meyerhof suggests the value of " $n$ " taken an average value from a distance of 0 to $B$ under the base of the foundation.

A. $Q A=12 \mathrm{~N}$; For width $\mathrm{B} \leq 1.2 \mathrm{~m}$

B. $\mathrm{QA}=8 \mathrm{~N}((\mathrm{~B}+0.3) / \mathrm{B})^{\wedge} 2$; for width $\mathrm{B}>1.2 \mathrm{~m}$

Where:

$\mathrm{QA}=$ Maximum support power

$\mathrm{N}=\mathrm{N}-\mathrm{SPT}$

$\mathrm{B}=$ Foundation Width

\subsection{Analysis Of Power Capacity To Support Clay (Meyerhof 1956 - 1974)}

For the foundation load in the form of squares, circles, and elongated foundations that lie in the soil of the clay, capacity supports the ultimate by observing the depth factor of the foundation, as follows:

$$
q_{u}=c_{u} N_{C}+D_{f} \gamma
$$


$q_{u n}=c_{u} N_{C}$

$\mathrm{qu}=$ capacity to support Ultimate $\left(\mathrm{kN} / \mathrm{m}^{2}\right)$

qun = capacity to support net Ultimate $\left(\mathrm{kN} / \mathrm{m}^{2}\right)$

$\mathrm{D}_{\mathrm{f}}=$ Depth of foundation $(\mathrm{m})$

$\gamma=$ weight of the soil volume $\left(\mathrm{kN} / \mathrm{m}^{3}\right)$

$\mathrm{c}_{\mathrm{u}}=$ cohesion in undrained condition $\left(\mathrm{kN} / \mathrm{m}^{2}\right)$

3.9 Analysis Of Power Capacity To Support The Sand (Meyerhof 1956 - 1974)

Granular soil types do not have cohesion (c) or have little cohesion. This granular soil usually forms a supporting capacity, especially by Relative Density (Df). Groundwater position against the foundation.

For granular or sandy soils, because cohesion $\mathrm{C}=0$ The equation of soil buffer capacity for elongated shaped foundations is as follows:

Where: $\mathrm{qu}=\mathrm{yDN}_{\mathrm{q}}+0.5 \mathrm{By} \mathrm{N}_{\mathrm{y}}[10]$

$\mathrm{Y}=$ Weight Unit

$\mathrm{D}=$ Depth of foundation

$\mathrm{B}=$ Foundation Diameter

$\mathrm{NQ}+\mathrm{Ny}=$ factor - support capacity factor

\subsection{Analysis of Plaxis 2D Data}

The Plaxis $2 \mathrm{D}$ is a two-dimensional element program developed for the analysis of deformation, stability, and groundwater flow in geotechnical engineering (Brinkgreve et al., 2016; Vickneswaran and Ravichandran, 2020; Jadid et al., 2020; Vali et al., 2018). PLAXIS 2D geometry models can be easily defined in-ground and structure modes after an independent solid model can automatically be cut and fused. The staged construction mode enables to simulate the construction and digging processes by enabling and disabling ground clusters and structural objects.

\section{Result and Discussion}

\subsection{Sieve Analysis}

\subsubsection{Drill Sample 1 (depth 4.50 - 5.00 M)}

Calculation of Sieve analysis on Drill Sample 1 (depth 4.50$5.00 \mathrm{M})$ (Table 1) shows the result as below.

Table 1. Calculation tables of Sieve analysis on Drill Sample 1 (4.505.00) M.

\begin{tabular}{|c|c|c|c|c|c|}
\hline \multicolumn{2}{|c|}{ FILTER SIZE } & \multirow{2}{*}{$\begin{array}{c}\text { HEAVY } \\
\text { RESTRAINE } \\
\text { D }\end{array}$} & \multirow{2}{*}{$\begin{array}{c}\text { AMOUN } \\
\text { T OF } \\
\text { WEIGHT } \\
\text { HELD }\end{array}$} & \multicolumn{2}{|c|}{ PERCENTAGE } \\
\hline $\mathrm{Mm}$ & $\mathrm{INCH}$ & & & $\begin{array}{c}\text { STUC } \\
\mathrm{K}\end{array}$ & ESCAPE \\
\hline 9,5 & $3 / 8$ & 0,00 & 0 & 0 & 100,000 \\
\hline 4,75 & NO \# 4 & 0,00 & 0 & 0 & 100,000 \\
\hline 2,36 & NO \# 10 & 8 & 8 & 3,186 & 96,814 \\
\hline 1,18 & NO \# 20 & 118,30 & 126,3 & 50,302 & 49,698 \\
\hline 0,6 & NO \# 40 & 80,90 & 207,2 & 85,522 & 17,478 \\
\hline 0,3 & NO \# 80 & 27,90 & 235,1 & 93,634 & 6,366 \\
\hline 0,15 & NO \# 100 & 1,70 & 236,8 & 94,311 & 5,689 \\
\hline 0,075 & NO \# 200 & 4,90 & 241,7 & 96,263 & 3,737 \\
\hline
\end{tabular}

The sieve size $3 / 8$ in getting weight-held in 0.00 , which indicates no samples restrained at the size of this $3 / 8$ sieve with a percentage of escaping $100 \%$.

The Sieve size No. 4 in the weight is 0.00 which indicates that there is no sample held on the size of the Sieve No. 4 with a percentage of a breakout of $100 \%$.

Size of filter No. 10 obtained weight 0.00 which indicates that no sample is held at the size of this No. 10 sieve with a percentage of a breakout of $100 \%$.

Size of filter No. 20 obtained 26 GR held weight with a percentage held at $17.35 \%$ and the percentage of RP $82.641 \%$.
Size of filter No. 40 was obtained the weight of $51.30 \mathrm{gr}$ with the amount of weight held to be $77.3 \mathrm{Gr}$. Percentage held at $51.61 \%$ and percentage escaped by $48.350 \%$.

55.80 GR held the size of filter No. 80 obtained weight with the amount of weight held to be 133.1 Gr. Percentage held at $88.86 \%$ and percentage escaped by $11.134 \%$.

Size of filter No. 100 obtained weight was held by $2.50 \mathrm{GR}$ with the amount of weight held to be $135.6 \mathrm{Gr}$. Percentage held at $90.53 \%$, and percentage escaped by $9.465 \%$.

The size of the filter No. 200 is obtained by the weight of 7.60 gr with the amount of weight held to be $143.2 \mathrm{Gr}$. Percentage held at $95.610 \%$ and percentage escaped by $4.390 \%$.

The result of the projection of the calculation value in the analysis sieve graph (Figure 2) obtained a group 1 curve shape that is categorized as medium-size sand with poor gradation according to the $\mathrm{Cu}$ and $\mathrm{Cz}$ values that can be because the sand has a uniform grain size.

Based on the test of the sieve analysis that is done, get results on the 200 no sample of soil type that passes by the amount of $<50 \%$. Based on USCS category, in this case, samples are included in the $S$ (sand) types, according to the sample in the analysis. According to the USCS criteria for poorly graded soil, if it has a smaller $\mathrm{Cu}$ of 5 and has a $\mathrm{Cz}$ between 0.5 to 2.0 indicating well-graded soil, it can be concluded that the soil is well graded. Good gradated soil will have $\mathrm{Cu}>4$, and $\mathrm{Cc}$ between 1 and 3 for gravel land and sand has $\mathrm{Cu}>6$ with $\mathrm{Cc}$ between 1 and 3 .

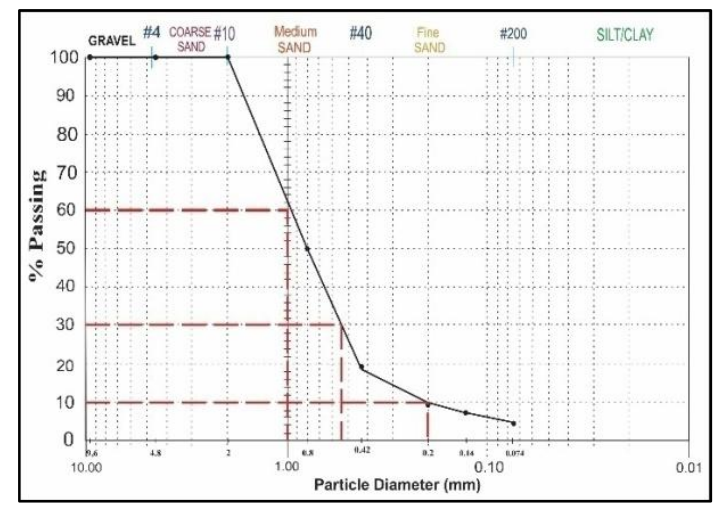

Fig. 2. Graph Sieve analysis on Drill Sample 1 (4.50-5.00) M.

\subsubsection{Drill Sample 2 (depth 8.00 - $8.50 \mathrm{M}$ )}

Calculation of Sieve analysis on Drill Sample 1 (depth 8.00$8.50 \mathrm{M}$ ) (Table 2) shows the result as below.

Table. 2. Calculation of Sieve analysis on Drill Sample 2 (depth 8.00$8.50 \mathrm{M})$.

\begin{tabular}{c|c|c|c|c|c}
\hline \multicolumn{2}{c|}{ FILTER SIZE } & \multirow{2}{*}{ HEAVY } & AMOUN & \multicolumn{2}{c}{ PERCENTAGE } \\
\cline { 1 - 1 } Mm & INCH & $\begin{array}{c}\text { RESTRAINE } \\
\text { D OF }\end{array}$ & WEIGHT & STUC & K \\
& & & HELD & ESCAPE & \\
\hline 9,5 & $3 / 8$ & 0,00 & 0 & 0 & 100,000 \\
4,75 & NO \# 4 & 0,00 & 0 & 0 & 100,000 \\
2,36 & NO \# 10 & 0 & 0 & 0,000 & 100,000 \\
1,18 & NO \# 20 & 26 & 26,0 & 17,359 & 82,641 \\
0,6 & NO \# 40 & 51,3 & 77,3 & 51,610 & 48,390 \\
0,3 & NO \# 80 & 55,8 & 133,1 & 88,866 & 11,134 \\
0,15 & NO \# 100 & 2,5 & 135,6 & 90,535 & 9,465 \\
0,075 & NO \# 200 & 7,6 & 143,2 & 95,610 & 4,390 \\
\hline
\end{tabular}

The size of the sieve $3 / 8$ to get a weight held in 0.00 which indicates that no samples were restrained at the size of this $3 / 8$ sieve with a percentage of escaping $100 \%$

The size of Sieve No. 4 in weight is 0.00 , which indicates that there is no sample held on the size of the Sieve No. 4 with a percentage of a breakout of $100 \%$. 
Size of filter No. 10 obtained weight held by 8 GR with a percentage held at $3.186 \%$ and the percentage of RP $96.814 \%$.

Size of filter No. 20 was obtained weight was held at 118.30 GR with the amount of weight held to 126.3 gr percentage was held by $50.302 \%$ and the percentage passed by $49.698 \%$

Size of filter No. 40 was obtained the weight of $80.90 \mathrm{gr}$ with the amount of weight held to be $207.2 \mathrm{Gr}$. Percentage held at $82.52 \%$ and percentage escaped by $17.478 \%$

27.90 GR held the size of filter No. 80 obtained weight with the amount of weight held to be 235.1 Gr. Percentage held at $93.634 \%$ and percentage escaped by $6.366 \%$

Size of filter No. 100 obtained weight was held by 1.70 GR with the amount of weight held to be $236.8 \mathrm{Gr}$. Percentage held at $94.311 \%$ and percentage escaped by $5.689 \%$

The size of the filter No. 200 is obtained by the weight of $4.90 \mathrm{gr}$ with the amount of weight held to be $241.7 \mathrm{Gr}$. Percentage held at $96.263 \%$ and percentage escaped by $3.737 \%$.

Results of projection of calculation value on graph sieve analysis (Figure 3), obtained form The Class 1 curve is categorized as a medium-size sand with poor gradation according to the $\mathrm{Cu}$ and $\mathrm{Cz}$ values that can be because the sand has a uniform grain size.

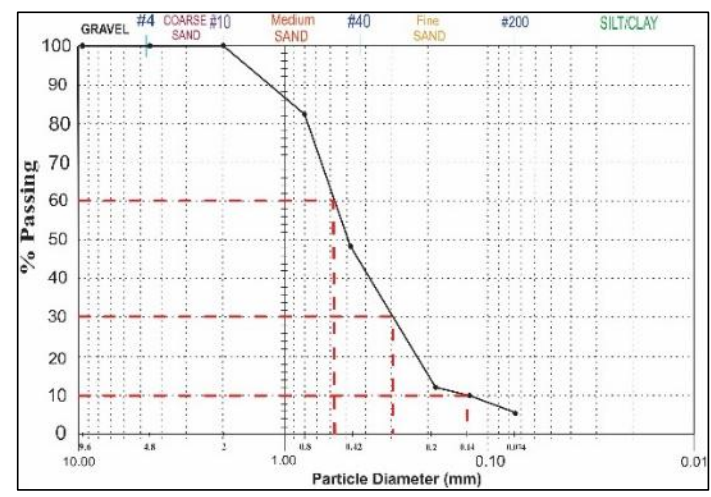

Fig. 3. Graph Sieve analysis on Drill Sample 1 (8.00-8.50) M.

According to the USCS criteria for the soil to graded well when it has a $\mathrm{Cu}$ greater than 5 and has a $\mathrm{Cz}$ between 0.5 to 2.0 indicating good graded soil, it can be concluded that the soil is a bad gradation. Well graded soil will have $\mathrm{Cu}>4$ and $\mathrm{Cc}$ between 1 and 3 for gravel soil, and sand has $\mathrm{Cu}>6$ with $\mathrm{Cc}$ between 1 and 3 .

\subsubsection{Calculation of Sieve analysis on Drill Sample 3 (depth 8.00-8.50 M)}

The size of the sieve No. 3/8 (Table 3 ), the weight of soil is $0.00 \mathrm{GR}$, which is that no grain is stuck on this filter, and the amount of the weight of the rate is $0 \mathrm{gr}$. While the percentage of grain size is $0.000 \%$ and the percentage of escaped is still $100,000 \%$.

Size of Sieve No. 4 weight of the soil is 0.00 GR, which is that no grain is stuck in this filter, and the amount of weight is the rate of $0 \mathrm{gr}$. While the percentage of the size of the weighted grain is $0.000 \%$, and the percentage escaped is still $100,000 \%$.

Size of sieve No. 10 weight of the soil is $0.40 \mathrm{GR}$, which is the details that are held Disaringan. This is included in the fine grain, and the amount of the weight of the rate is 0.4 gr. While the percentage of the size of the weighted grain is $0186 \%$, and the percentage passes the size of $99,814 \%$.

Size of sieve No. 20 weight soil is $46.30 \mathrm{gr}$, which is the details that are held Disaringan. This is included in the fine grain-medium and the amount of the weight of the $46.7 \mathrm{gr}$. While the percentage of the size of the weighted grain is $21,763 \%$, and the percentage passes the size of $78,237 \%$.

The size of the sieve No. 40 the soil weight is $97.40 \mathrm{gr}$, which is the details that are held in the sieve. It is included in coarse grain, and the current amount weight is $144.1 \mathrm{gr}$, while the percentage of the size of the grain measure is $67,154 \%$, and the percentage passes by $32,846 \%$.

Size of Sieve No. 80 the soil weight is $54.40 \mathrm{gr}$ which is the details that are held Disaringan is included in the fine grainmedium, and the amount of the weight of the $198.5 \mathrm{Gr}$. While the percentage of the size of the weighted grain is $92,505 \%$, and the percentage passes the size of $7,495 \%$.

Size of sieve No. 100;soil weight is 2.20 gr.Fine-grain restrained in the sieve with the weight amount of $200.7 \mathrm{Gr}$. The grain weight size percentage is $93,530 \%$, and the pass size percentage is $6,470 \%$.

Size Sieve No. 200 the soil weight is 5.10 gr which is the details that are held in the sieve included in the fine-grain and the amount of the weight of the $205.8 \mathrm{Gr}$. While the percentage of the weighted grain size is $95,907 \%$ and the percentage passes the size of the grain $4,093 \%$.

Uniformity Coefficient $(\mathrm{Cu})$ samples of the soil are 3,714, which is included in the poor gradation category, which is smaller than 5. While the gradation coefficient $(\mathrm{Cz})$ sample of the soil is 1.2363 (Figure 4).

The value of the resulting chart derived from D60, D30, and D10 data, where the maximum of the D60 is the diameter passed at $60 \mathrm{~mm}$ sieve size, as well as the D30 is the diameter passes at a 30mm sieve size, and the D60 is diameter qualified at $10 \mathrm{~mm}$ sieve size.

Table. 3. Calculation of Sieve analysis on Drill Sample 3 (depth 8.00$8.50 \mathrm{M})$.

\begin{tabular}{c|c|c|c|c|c}
\hline \multicolumn{2}{c|}{ FILTER SIZE } & \multirow{2}{*}{$\begin{array}{c}\text { HEAVY } \\
\text { Mm }\end{array}$} & $\begin{array}{c}\text { AMOUN } \\
\text { T OF }\end{array}$ & \multicolumn{2}{c}{ PERCENTAGE } \\
\cline { 1 - 1 } & INCH & $\begin{array}{c}\text { RESTRAINE } \\
\text { D }\end{array}$ & $\begin{array}{c}\text { WEIGHT } \\
\text { HELD }\end{array}$ & $\begin{array}{c}\text { STUC } \\
\text { K }\end{array}$ & ESCAPE \\
\cline { 1 - 1 } 9,5 & $3 / 8$ & 0,00 & 0 & 0,000 & 100,000 \\
4,75 & NO \# 4 & 0,00 & 0 & 0,000 & 100,000 \\
2,36 & NO \# 10 & 0,40 & 0,4 & 0,186 & 99,814 \\
1,18 & NO \# 20 & 46,30 & 46,7 & 21,763 & 78,237 \\
0,6 & NO \# 40 & 97,40 & 144,1 & 67,154 & 32,846 \\
0,3 & NO \# 80 & 54,40 & 198,50 & 92,505 & 7,495 \\
0,15 & NO \# 100 & 2,20 & 200,7 & 93,530 & 6,470 \\
0,075 & NO \# 200 & 5,10 & 205,8 & 95,907 & 4,093 \\
\hline
\end{tabular}

According to the criteria from USCS, the soil is well-graded if it has a $\mathrm{Cu}$ greater than five and has a $\mathrm{Cz}$ between 0.5 to 3.0, indicating well-graded soil. It can then conclude the soil in the drill holes $8.00-8.50$ meters have a poor gradation because there are smaller $\mathrm{Cu}$ of 5 and have a good $\mathrm{Cz}$ because it has a gradation of not more than $3.0 \mathrm{~mm}$.

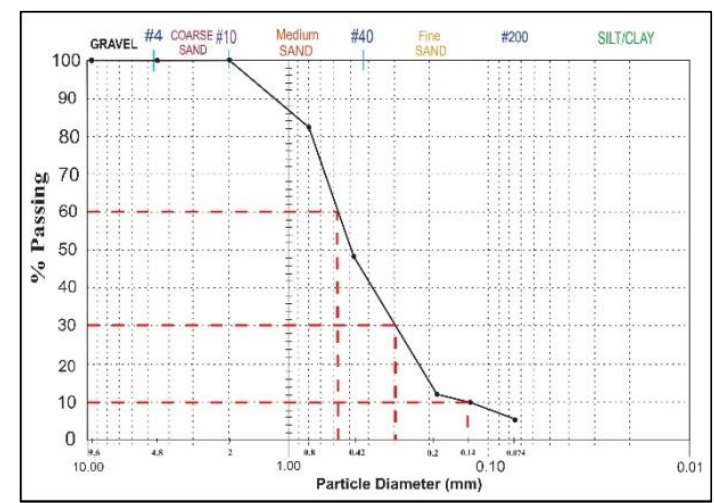

Fig. 4. Graph Sieve analysis on Drill Sample 3 (8.00-8.50) M.

\subsection{Atterberg Limit}

The first experiment had a water content of $32.8 \%$ with a low number of 11 times. The second attempt has a water content of $30.5 \%$ with a low number of 19 times. The third test has a water content of $27.9 \%$ with a blow count of 28 times. The 
fourth experiment had a water content of $26.2 \%$ with a low number of 38 times (Table 4).

From the experiments that have been carried out so that the average value of water content is 28.65 grams. With the number of beats averaging 24 times the tap.

\subsection{Standard Penetration Test ( $N$-SPT)}

\subsubsection{Analysis Power Capacity Calculation For Soil Support Through SPT Test}

The test for power capacity is necessary, and then it can be deduced increasingly in the drilling that is done then the type of soil gained will be more distinct-different and also the level of consistency is different so that at the time of Test N-SPT on soil that has a hard consistency will be done as much as 60 times the punch and on the soil that has a soft consistency feeding the amount of blow its SPT under 50 Based on the calculation of land support capacity through N-SPT test.

Table 4. Atterberg Limit Bore Hole 3at the depth 22.00-22.50 M.

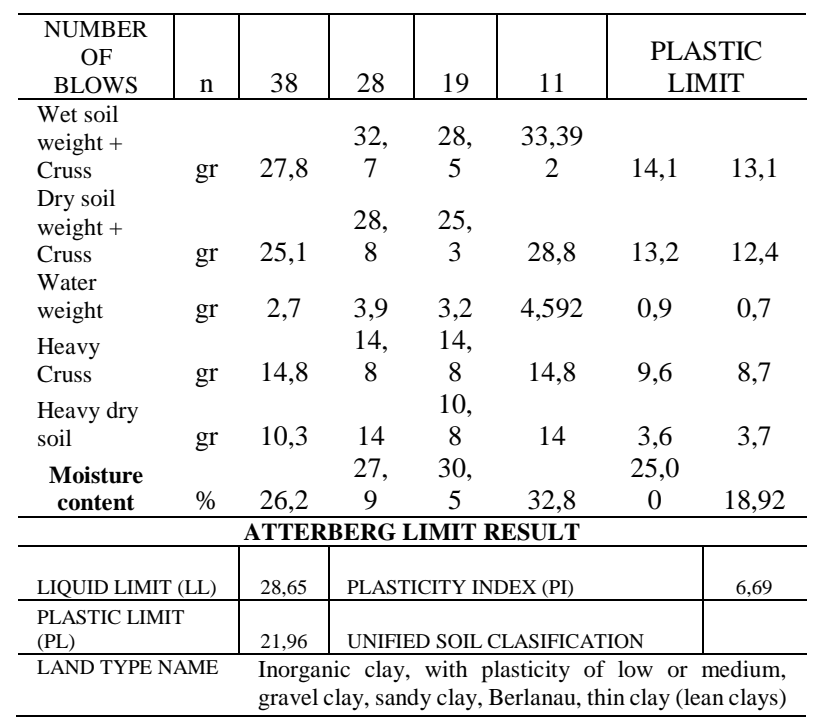

Table 5. Calculated Result Of Land Support Power Capacity Through Test N-SPT In Bore Hole 3.

\begin{tabular}{ccccccc}
\hline No & Depth & Soil Type & $\begin{array}{c}\text { N- } \\
\text { SPT }\end{array}$ & $\begin{array}{c}\text { B } \\
\text { OF } \\
\text { qa }=12 \\
\text { N }\end{array}$ & $\begin{array}{c}\text { Consistenc } \\
\text { y }\end{array}$ \\
\hline 1 & 1,00 & Sand clay & 2 & 1 & 24 & Very Soft \\
2 & 3,00 & Fine sand & 8 & 1 & 96 & Soft \\
3 & 5,00 & Fine sand & 10 & 1 & 120 & Soft \\
4 & 7,00 & Fine sand & 15 & 1 & 180 & Medium \\
5 & 9,00 & Fine sand & 16 & 1 & 192 & Medium \\
6 & 11,00 & Fine sand & 20 & 1 & 240 & Medium \\
7 & 13,00 & Fine sand & 24 & 1 & 288 & Medium \\
8 & 15,00 & Sand & 60 & 1 & 720 & Very Hard \\
9 & 17,00 & Sand & 60 & 1 & 720 & Very Hard \\
10 & 19,00 & Sand & 60 & 1 & 720 & Very Hard \\
11 & 21,00 & Sand & 60 & 1 & 720 & Very Hard \\
12 & 23,00 & Clay & 22 & 1 & 264 & Very Hard \\
13 & 25,00 & Clay & 26 & 1 & 312 & Very Hard \\
14 & 27,00 & Clay & 31 & 1 & 360 & Hard \\
15 & 29,00 & Clay & 21 & 1 & 252 & Very Hard \\
16 & 31,00 & Clay & 35 & 1 & 420 & Hard \\
17 & 33,00 & Sand & 37 & 1 & 444 & Hard \\
18 & 35,00 & Sand & 58 & 1 & 696 & Very \\
& & & & & & Hard \\
19 & 37,00 & Sand & 60 & 1 & 720 & Very \\
& & & & & & Hard \\
20 & 39,00 & Sand & 60 & 1 & 720 & Very \\
21 & 41,00 & Sand & 60 & 1 & 720 & Hard \\
\hline & & & & & & \\
\hline
\end{tabular}

If the value of N-SPT obtained is big then the capacity to support the land will be greater and vice versa if the value of $\mathrm{N}$ SPT is small, the capacity of the supporting power is smaller so that when implanted the foundation of the small N-SPT value bridge pole will multiply a large decline, so it can be concluded that the value of $\mathrm{N}$ - The soil type that has a small $\mathrm{n}$-SPT value is the clay and silt soils and the type of soil that has a large $\mathrm{N}$ SPT value is the sandy soil because the sandy soil does not have a liquid boundary and a plastic boundary so that the sand can not keep the water and the sand soil also has bad porosity. Then in the land of clay and silt has a liquid boundary and a plastic boundary so that the soil type of clay and silt has soil properties that can stray water. If the foundation of the pole is implanted in the soil of the clay and eat water will occur a large decline because the clay and silt can not withstand a large burden, then if the foundation to be implanted bridge pole should be implanted on the type of sand soil because this type of sand soil can withstand a large burden because the greater the burden received by the sand to lowing the land

\subsubsection{Calculation Of N-Spt Test On Sand Soil}

On the depths of the $08.00-08.50$ meters (Table 5), deep sand can support large soils. So that at the time of the foundation of the sand-covered soil, then the decline is very small because the sand can support a strong soil to withstand the burden it receives, it is advisable to plant the foundation of the bridge pole preferably in the sandy soil because the sand has the capacity of large soil support and when the drilling is done at sufficient depth in the advisable to obtain the Then for the sand can support a large license, because the sand can support permit up to 200 which means good enough if implanted the foundation of the bridge pole.

Table 6. Calculation Of N-Spt Test On Sand Soil.

\begin{tabular}{c|c|c|c|c|c}
\hline Depth & $\begin{array}{c}\text { Soil } \\
\text { Layer }\end{array}$ & $\begin{array}{c}\text { Large } \\
\text { angle }(\Phi) \\
=\mathrm{N}_{\mathrm{q}}, \mathrm{N}_{\mathrm{y}}\end{array}$ & $\begin{array}{c}\text { Unit } \\
\text { Wight } \\
\left(\mathrm{kN} / \mathrm{m}^{2}\right)\end{array}$ & $\begin{array}{c}\text { Diameter } \\
\text { Bore (B) }\end{array}$ & $\begin{array}{c}\text { Meyerhof } \\
\mathrm{qu}= \\
\mathrm{kN} / \mathrm{m}^{2}\end{array}$ \\
\hline 08.00 & Sand & $\mathrm{N}_{\mathrm{q}}=18,4$ & 1,265 & $1 \mathrm{~m}$ & 200,123 \\
- & & $\mathrm{N}_{\mathrm{y}}=22,0$ & $\mathrm{kN} / \mathrm{m}^{2}$ & & $\mathrm{kN} / \mathrm{m}^{2}$ \\
08.50 & & &
\end{tabular}

\subsubsection{Calculation Of N-SPT Test On Clay}

The soil of the clay depth $22.00-22.50$ meters has the capacity of small soil so that when planted the foundation of the clay soil in the field, there will be a decline due to heavy loads will affect the condition of the land strength at the time of the burden that is working. So to plant a foundation in the clay land is not advised even if done deep drilling, the clay will not be strong withstand the burden received and the capacity of the land support the clay is very small, and consistency in this layer of clay is soft to medium.

Table 7. Calculation Of N-Spt Test On Clay Soil.

\begin{tabular}{l|l|l|l|l|l}
\hline Depth & $\begin{array}{l}\text { Soil } \\
\text { Layer }\end{array}$ & $\begin{array}{c}\text { Large } \\
\text { Angel } \\
(\Phi)=\mathrm{N}_{\mathrm{c}}\end{array}$ & $\begin{array}{c}\mathrm{Cu} \\
(\mathrm{kN} / \\
\left.\mathrm{m}^{2}\right)\end{array}$ & $\begin{array}{c}\text { Unit } \\
\text { Weight } \\
\left(\mathrm{kN} / \mathrm{m}^{2}\right)\end{array}$ & $\begin{array}{c}\text { Meyerhof } \\
\mathrm{qu}= \\
\mathrm{kN} / \mathrm{m}^{2}\end{array}$ \\
\hline $\begin{array}{l}22.00- \\
22.50\end{array}$ & $\begin{array}{l}\text { Silty - } \\
\text { Clay }\end{array}$ & $\begin{array}{l}\mathrm{N}_{\mathrm{c}}= \\
14,83\end{array}$ & $\begin{array}{l}72,60 \\
\mathrm{kN} / \mathrm{m}\end{array}$ & $\begin{array}{l}1,799 \\
\mathrm{kN} / \mathrm{m}^{2}\end{array}$ & $\begin{array}{c}66,248 \\
\mathrm{kN} / \mathrm{m}^{2}\end{array}$ \\
\hline
\end{tabular}

The depth of sand soil type $08.00-08.50$ meters have the value of the capacity of the large soil support with a value of $200,123 \mathrm{KN} / \mathrm{m} 2$ so that at this depth the decline is small and at a depth of 22.00-22.50 meters acquired soil type is the form of clay and silt which has the value of capacity of small soil support that will cause the decline will be greater. Then it is recommended to embed the foundation of the bridge pole should have the value of the capacity of the large land support 
to be exposed to the burden on the foundation of the bridge pole decline that occurs in the land will be smaller.

\subsection{Plaxis Modelling}

\subsubsection{Plaxis Modelling Power Capacity To Support Land}

Increasingly in the drill done and large loads received by the soil, then the capacity of land support will influence on the foundation of the pole so that it can cause the slope of the Pole Foundation (Figure 5).

The greater the NSPT value that can be, then the smaller the decline that occurs, so too, the smaller the NSPT value that can be, then the greater the decline that occurs.

The depth of 00-01.00 M is obtained by a large reduction of NSPT value of 10 with the lithology of flared-sand and smooth consistency with the loose grain.

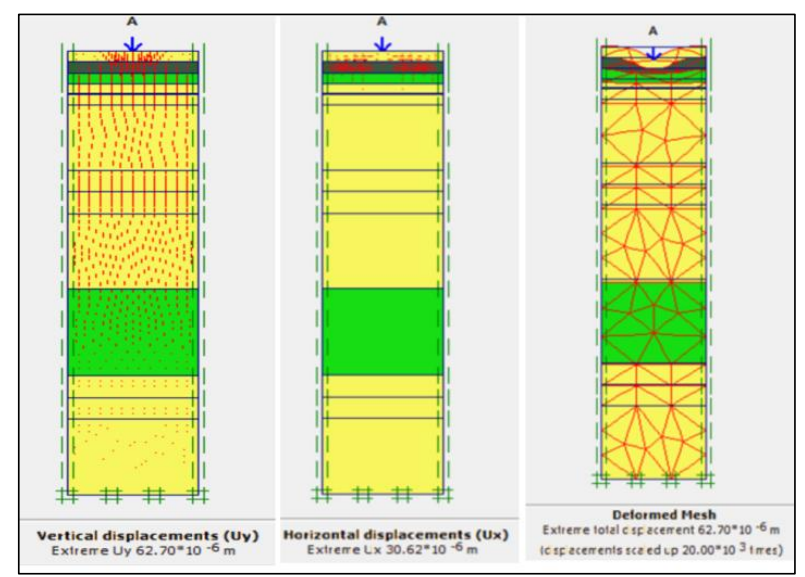

Fig. 5. Plaxis Modelling Power Capacity To Support Land.

Depth of 3-7 meters is ground domination with fine sand granules with NSPT value of 11-30 so that the soil at this depth categorized as soil with medium consistency.

The depth of 9-13 meters is ground domination with finegrained sand grains with an NSPT value of $31-50$ so that the soil at this depth is categorized as ground with Stiff (rigid) consistency with dense density.

Depth of 13-15 meters is ground domination with fine sand grains with an NSPT value of $>50$ so that the soil at this depth is categorized as ground with a very stiff consistency (very rigid) - Hard (hard) with a relatively dense.

Depth of 15-35 M is ground domination with granular sand - loam with NSPT value of $<60$ and $>10$ so that the soil at this depth is categorized as soil with medium-stiff consistency (rigid) with medium-dense relative density (dense).

Based on the calculations, it can be seen a large NSPT value as well as large impairment value occurs in drill 1 holes with soil type contained in each depth, and also the consistency of each at any depth. From these two charts can be concluded the greater the value of NSPT that canbe, then the smaller the decline in the value of each depth, N-SPT values that can relate to the soil type and also the consistency of each depth.Sand has a large N-SPT value because it has no liquid and plastic properties, which sand can drain the water more easily. After all, it has pores, and the loam or silt usually has a relatively large $\mathrm{N}$-SPT value because the clay or silt has soft soil properties that have plastic boundaries and liquid boundaries, which are not able to pass the water. But the type of soil that can be sometimes unbiased to be a reference for the value of N-SPT that is found, for example, can be seen at a depth of 5 meters, which has a relatively small N-SPT value and a large decline, which affects the depth of this is the groundwater face. Because the groundwater in Bor 1 is at a depth of 4 meters.

\subsubsection{Plaxis Modeling On Declining Soil}

The first image in getting deformed mash land drop profile. This deformed function to show a large decrease in the land that occurs can be seen in the soil that decreases. The decline occurred at a depth of $00.00-03.00$ meters, on the layer of piles of soil material.The decline was shown by the direction of the blue-colored arrow that leads vertically. The load point is given in the center of the layer.

The second image is for getting a displacement vertical land drop profile. The vertical image shows the direction of pressure or stress and the load given on the ground at the center of the soil layer and gets red stripes on the layer, which means the soil obtains the pressure of the ground.On the upper part receives a pressure greater than the bottom, which means from top to bottom is decreased pressure gained on the ground. The decline occurs as deep as 20.77 x 10-3 M. or $2.077 \mathrm{~cm}$ (Figure 6).

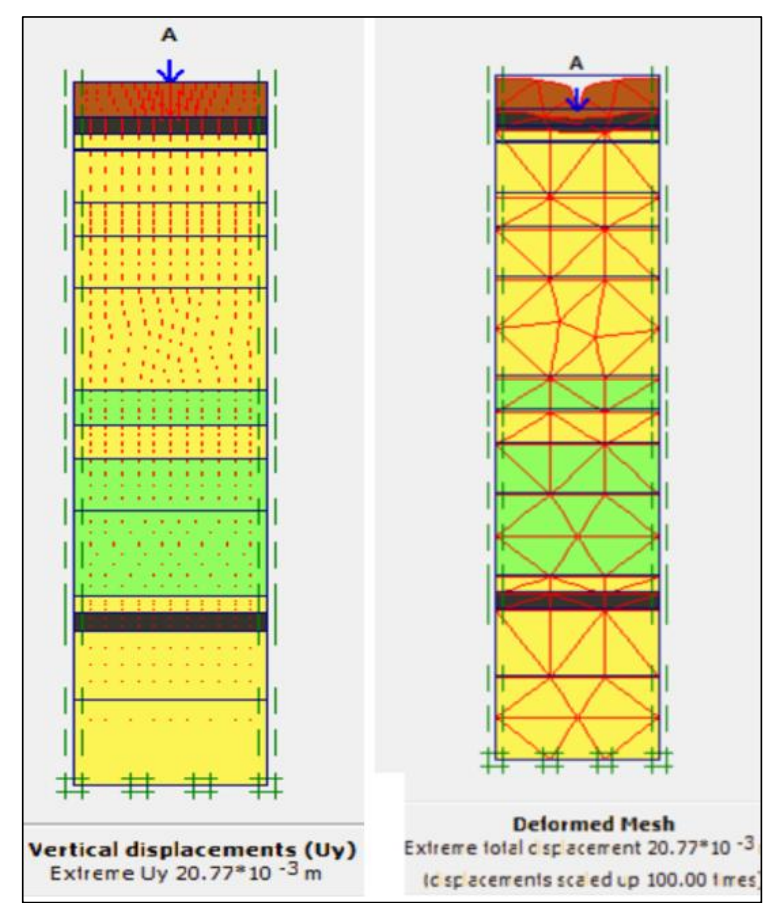

Fig. 6. Plaxis Modeling On Declining Soil.

\section{Conclusion}

The calculation of the filter analysis in drill with depth (4.50-5.00) and (8.00-8.50) meters, it indicates that the sample is categorized as fine soil has poor grain uniformity, because in the sample (4.50-5.00) The meter has a value of $\mathrm{Cu} 3.714$, and in the sample $(8.00-8,50)$ meter has a value of 4 . Included in the category of bad graded soil. All the tests Comply with ASTM, AASHTO, and USCS standards.

At the depth $(22.00-22.50)$ at a rate of water at an average of 18.92 grams. With an average beat amount of 24 beats. The average value of the plastic sample rate at this depth is $21.96 \%$, and the value of the plastic index at this depth is $6.69 \%$. Plastic indices get through the calculation of liquid limit - plastic limit.

The decline also influenced by the value of NSPT that can, if the soil type is sandy but has a small NSPT value then the decline is also greater and vice versa.

Based on the results of the sieve analysis and Atterberg connection limit on the capacity of the land support, it can be 
conditioned for the foundation strength of the pole. It should be implanted at depth to obtain the type of soil that does not have a plastic boundary and liquid boundaries that the plastic boundary and liquid limits save water content that will affect the foundation of the pole.

\section{References}

Bardet, J.P., 1997. Experimental soil mechanics (p. 582). Upper Saddle River, NJ: Prentice Hall.

Bautista-De Castro, Á., Sánchez-Aparicio, L.J., CarrascoGarcía, P., Ramos, L.F. and González-Aguilera, D., 2019. A multidisciplinary approach to calibrating advanced numerical simulations of masonry arch bridges. Mechanical Systems and Signal Processing, 129, pp.337-365.

Brinkgreve, R.B.J., Kumarswamy, S., Swolfs, W.M., Waterman, D., Chesaru, A. and Bonnier, P.G., 2016. PLAXIS 2016. PLAXIS bv, the Netherlands.

Chai, J., Suddeepong, A., Liu, M.D. and Yuan, D.J., 2017. Effect of daily fluctuation of groundwater level on landsubsidence. International Journal of Geosynthetics and Ground Engineering, 3(1), p.1.

Clarke, M.C.G., Kartawa, W., Djunuddin, A., Suganda, E. and Bagdja, M., 1982. Geological Map of The Pakanbaru Quadrangle. Sumatra. PPPG.

Deng, Y., Cai, C., Xia, D., Ding, S., Chen, J. and Wang, T., 2017. Soil Atterberg limits of different weathering profiles of the collapsing gullies in the hilly granitic region of southern China. Solid Earth, 8(2), p.499.

Gupta, R., Goyal, K. and Yadav, N., 2016. Prediction of safe bearing capacity of noncohesive soil in arid zone using artificial neural networks. International Journal of Geomechanics, 16 (2), p.04015044.

Hamid, K.A., Soegiarso, R., Hardjomuljadi, S., Setiawan, M.I., Abdullah, D. and Napitupulu, D., 2018, November. Model of Organizational Effectiveness Project Management on Infrastructure Development in Ministry of Public Works and Housing Republic of Indonesia. In Journal of Physics: Conference Series (Vol. 1114, No. 1, p. 012129). IOP Publishing.

Hamzaban, M.T., Tavana, N.H., Jakobsen, P.D. and Bagheriyan, A.R., 2019. The effect of the plastic behavior of clay particles on LCPC abrasive coefficient. Tunnelling and Underground Space Technology, 92, p.103054.

Jadid, R., Montoya, B.M., Bennett, V. and Gabr, M.A., 2020. Effect of repeated rise and fall of water level on seepage-induced deformation and related stability analysis of Princeville levee. Engineering Geology, 266, p.105458.

Kumar, A. and Mondal, J.K., 2017. Newly developed MATLAB based code for equivalent linear site response analysis. Geotechnical and Geological Engineering, 35(5), pp.2303-2325.

Kuzu, T., Oki, H., Yoshiro, I. and Trinh, N.T.T., 2020.
Evaluation of Bearing Capacity of Steel Rotation Pile. In Geotechnics for Sustainable Infrastructure Development (pp. 169-176). Springer, Singapore.

Laksono, T.D., Kurniasih, N., Hasyim, C., Setiawan, M.I. and Ahmar, A.S., 2018, January. The Impact of Airport Performance towards Construction and Infrastructure Expansion in Indonesia. In Journal of Physics: Conference Series (Vol. 954, No. 1, p. 012015). IOP Publishing.

Persada, C., Sitorus, S.R.P. and Djakapermana, R.D., 2018, March. Policy model of sustainable infrastructure development (case study: Bandarlampung City, Indonesia). In IOP Conference Series: Earth and Environmental Science (Vol. 124, No. 1, p. 012008). IOP Publishing.

Rehman, H.U., Kayabali, K., Tall, A., Knadel, M., de Jonge, L.W. and Arthur, E., 2019. Predicting coefficient of linear extensibility and Atterberg limits of fine-grained soils using vis-NIR spectra. In 2018-2019 SSSA International Soils Meeting.

Ruiz-Martínez, G., Rivillas-Ospina, G.D., Mariño-Tapia, I. and Posada-Vanegas, G., 2016. SANDY: A Matlab tool to estimate the sediment size distribution from a sieve analysis. Computers \& geosciences, 92, pp.104-116.

Salim, W. and Negara, S.D., 2018. Infrastructure development under the Jokowi administration: Progress, challenges and policies. Journal of Southeast Asian Economies, 35 (3), pp.386-401

Ubani, C.E., Ani, G.O. and Womiloju, T.T., 2018. Permeability Estimation Model from Grain Size Sieve Analysis: Data of Onshore Central Niger Delta. European Journal of Engineering Research and Science, 3(12), pp.119-125.

Vali, R., Saberian, M., Li, J., Shams, G. and Gelder, P.V., 2018. Properties of geogrid-reinforced marine slope due to the groundwater level changes. Marine Georesources \& Geotechnology, 36(6), pp.735-748.

Vickneswaran, T. and Ravichandran, N., 2020, February. Multi Hazard Analysis of Earth Slopes Using Coupled Geotechnical-Hydrological Finite Element Model. In Geo-Congress 2020: Engineering, Monitoring, and Management of Geotechnical Infrastructure (pp. 6069). Reston, VA: American Society of Civil Engineers.

Wafi, A., Sasmito, P., Rizki, M.A. and Rahman, A., 2018 , April. Comparison Analysis Of Subsurfaces Survey Between Geophysics Method (Geoelectric/Ert) And Geotechnical Method (Standard Penetration Test (Spt) At Kaima Overpass Manado-Bitung Toll Road. In EAGE-HAGI 1st Asia Pacific Meeting on Near Surface Geoscience and Engineering (Vol. 2018, No. 1, pp. 1-6). European Association of Geoscientists \& Engineers the CC BY-SA License (http://creativecommons.org/licenses/by-sa/4.0/). 